Gynecologic and

Obstetric Investigation
Gynecol Obstet Invest 2016;81:105-111

DOI: $10.1159 / 000435880$
Received: January 20, 2015

Accepted after revision: June 11, 2015

Published online: August 20, 2015

\title{
Jewish Law, Scarcity of Sperm Donors and the Consequent Private Import of Sperm of Non-Jews by Israeli Women
}

\author{
Ya'arit Bokek-Cohen \\ Department of Sociology and Anthropology, Ariel University, Ariel, Israel
}

\section{Key Words}

Artificial insemination · Judaism · Religion · Sperm banks ·

Tissue donors

\begin{abstract}
Aim: The objective of this article is to explore how Israeli Jewish women cope with the religious prohibition on sperm donation and the scarcity of Israeli donors, and to estimate the number of available sperm donors in Israel. Methods: A key word search was employed to retrieve relevant Hebrew and English sources; additional information was collected via interviews with two sperm donors and twelve donor insemination patients. Results: Rabbinical instructions focus on married women and refrain from acknowledging the growing number of non-married donor insemination patients. Nonmarried women follow the restrictions relevant to married women and hence refrain from purchasing Jewish sperm. Israeli sperm banks offer donations of Jewish donors whose number is estimated at a maximum of 140 and a minimum of 50 for the entire Jewish population of 6.2 million. In order to abide by American Society for Reproductive Medicine recommendations, the number of available donors should optimally be six times larger. The scarcity of sperm donors drives the private import of American sperm donations. Conclusion: Reconsideration of the rabbinical prohibition to al-
\end{abstract}

low collecting sperm for donating to women who wish to have a baby is needed for the sake of increasing the donor pool, along with measures to ensure donors' privacy and dignity.

(c) 2015 S. Karger AG, Basel

\section{Introduction}

Currently Jewish couples who wish to obey religious law and also to avoid the possibility of consanguineous relationships of their future donor offspring prefer to turn to American sperm banks to purchase semen from non-Jewish donors. In addition Israel, like other Western societies, has witnessed a growing number of non-married women seeking donor insemination (DI) [1-3]. The legal entitlement of Israeli non-married women to DI services was first recognized in 1988; however, until 1997 they suffered from a discriminatory policy and were requested to both have a psychiatric diagnosis as well as the approval of a social worker attesting to fitness for motherhood [4]. The Israeli law does not instruct sperm banks to ask patients about their sexual orientation. Moreover, the sexual orientation of the increasing number of lesbian couples has had no impact on these women's quest for motherhood due to the pronatalist orientation of Jewish

\section{KARGER}

E-Mail karger@karger.com

www.karger.com/goi (c) 2015 S. Karger AG, Basel

0378-7346/15/0812-0105\$39.50/0
Ya'arit Bokek-Cohen

Department of Sociology and Anthropology

Ariel University, POB 3

IL-40700 Ariel (Israel)

E-Mail ybokek@gmail.com 
and Israeli culture [2-5], which is reflected in the average fertility rate of 3 , almost double the rate (1.74) in OECD countries. The family and childbearing are of supreme significance for Jewish Israelis, and hence the national health insurance covers most kinds of fertility treatments, which are fully subsidized for the first and second child for all Israeli women. Although most non-married DI patients in Israel are secular [1], the Halakha (traditional rabbinical Jewish law) plays a major role in formulating familial and medical policies, as well as personal preferences and decisions relating to these realms among the secular as well [3]. Understandably, Jewish tradition and culture impact on both sperm recipients and sperm donors alike. Hence, the aim of the present article is twofold: one is to explore the centrality of the religious influence over the choice of the sperm donor by married and nonmarried DI patients, and the other is to estimate the number of available sperm donors in Israel, which is not known by the Ministry of Health and by fertility practitioners [6]. The next section describes the methods used in the present inquiry.

\section{Methods}

This study was approved (before any data collection) by Institutional Review Board at Ariel University where the author is employed (IRB No. 153068). Approval was granted for all research methods planned for the study. Manual searches of international scientific publications focusing on the practice of DI, including limits on the number of births as well as unique rabbinical restrictions for Jewish DI patients, were conducted to identify the specific guidelines for women applying for DI treatment. The searches included both free text and indexed terms to maximize the relevance of the retrieved sources to the purpose of the study.

In order to assess the number of available sperm donors in Israel, twelve non-married DI patients treated at ten out of the thirteen public sperm banks were recruited via snowball sampling and also following an ad on two forums, one targeting single mothers and the other targeting lesbian couples. The sole criterion for inclusion was whether they had applied for DI and purchased sperm over the past 2 years. Telephone interviews were conducted with these women after scheduling a convenient time for holding the conversation. Five of the interviewees identified themselves as religious heterosexual women who had hoped to marry, but after they reached the age of 38-40, decided to have a baby on their own. The remaining seven interviewees were secular; three of them also identified themselves as heterosexual and the other four were living with a female partner. Although they were presented with various questions during the interview, the relevant question for the present article was how many donors in the catalogue each interviewee was offered and at which sperm bank. The goal was to find at least one DI patient from each of the thirteen public sperm banks, so when one patient of a specific bank was identified, no more efforts were made to look for additional patients. If two women who had previously been patients of the same bank agreed to be contacted by the author, they were nevertheless interviewed. Through the information provided by the twelve interviewees, data were obtained only for nine out of the thirteen public sperm banks in Israel.

With the aim of deepening the understanding of the lived experience of being a sperm donor in Israel, two donors agreed to be interviewed face to face. These donors were identified following an ad on three forums targeting recently discharged soldiers or those approaching their discharge from compulsory service. No monetary or other compensation was offered to prospective interviewees. Personal meetings with the donors were held at an unobtrusive table in a café of their choice; each one of the patients and donors was interviewed separately for about 2 hours, and the conversation was tape-recorded after receiving the interviewee's permission. One of the donors was a 27.5-year-old student who wished to donate to a private sperm bank because of the higher monetary compensation (about USD 200 per vial) as compared to that paid by a public bank (usually USD 120), but was rejected by private banks because his height was less than 5'9"; therefore, he could donate only to a public bank, and had been donating to that bank for 8 months at the time of the interview. The other donor was a 24 -yearold man over 6' 1 " tall and had been donating to two private banks over the past 1.5 years. The following section presents the main principles that inform Jewish DI patients and potential donors.

\section{Results}

\section{Rabbinical Instructions regarding DI Practices}

Since assisted reproductive technology (ART) is a recent medical advance, no guidance is provided directly in the Torah; therefore, halakhic difficulties and controversies abound [7]. Procreation is legitimate solely within the formal framework of religious marriage. Ejaculation of semen outside the context of intercourse is required for supplying the gametes that replace those of the infertile husband; however, it violates a halakhic prohibition known as hotza'at zera levatalah. This prohibition is based on the view that sperm is wasted, which is sinful in the eyes of God [8], because it jeopardizes the fulfillment of the first commandment of the Jewish Torah 'be fruitful and multiply' (Gen 1,21). For the same purported reason, scientists of Christian faith who studied sperm asked their subjects to collect their semen using rubber or skin condoms during intercourse [9]. Similarly, some rabbis allow the collection of semen during intercourse in a condom with a pinpoint hole, so sperm can theoretically reach the cervix $[10,11]$. Jewish Orthodox poskim (halakhic deciders) who follow stringent interpretations of the Scriptures refuse to allow it even for procreative purposes $[4,11]$, view sperm expulsion as the most severe sin for a Jewish male, and regard both fertility practitioners and sperm donors as violating the severe prohibition against mastur- 
bation; however, more lenient poskim tend to grant special permission (heyter) [7] on a case-by-case basis for achieving the procreative goals of married heterosexual couples exclusively. Among them, some approve that if all other methods cannot be used, the sperm may be obtained by masturbation aided by a mechanical stimulator, preferably operated by the doctor, although self-stimulation may also be allowed [11]. Although some rabbinical scholars consider a donor-conceived offspring a mamzer (i.e., offspring of a forbidden relationship), all poskim are unanimously against using sperm from a Jewish donor [11]. Some of them maintain that a married woman who was impregnated by a Jewish donor is to be considered as having committed adultery and hence must not remain married to her husband [7]. An additional concern relates to the potential of an unwitting marital relationship between siblings of the same donor; the chances of such incestuous relations are almost null when sperm is imported from non-Jews abroad. Therefore, all rabbis recommend avoiding the purchase of semen in Israel [2]. However, as regards the issue of intermarriage, the nonJewish genetic father is not considered the halakhic father of a child born to his Jewish wife. Such a child is Jewish and is considered halakhically fatherless [11]; this seems to be the equivalent of a case with a non-Jewish donor and a non-married DI patient. Generally speaking, halakhists do not fully trust the medical establishment's integrity; there is always the concern that unwanted sperm will be added to or substituted for that of the husband in order to increase the likelihood of a successful conception [11], a practice that may impinge upon the purity of the Jewish people as sacred and chosen by God. Although women of all marital status are entitled to ART by law [4], it seems that both Jewish poskim and fertility experts have not paid sufficient attention to the issue of halakhic regulation of DI for non-married women. Scientific publications that problematize the unique religious restrictions for ART patients who are religiously observant relate to heterosexual married couples, whereas there is silence regarding unmarried women. Women are expected to fulfill their maternal calling within the sacred institution of marriage; childbearing out of wedlock is ignored because of its problematic basis, as it challenges the most basic tenets of age-old Jewish belief.

Fertility tourism is an expensive alternative that is not cost-effective when compared to the cost of online purchase of semen from abroad. Hence, it is not practiced by Israelis seeking semen purchase, compared to other countries where it is more prevalent [12]. Because of the demand by mainly religious patients to have sperm from

Jewish Law and Private Import of Sperm of Non-Jews by Israeli Women
non-Jews, purchasing sperm from non-Jewish donors abroad is permitted by the Ministry of Health after the proper approvals, granted on a case-by-case basis [13]. Women are not allowed to import semen without involving an Israeli clinic. They do so only by registering at a private bank which has a business relationship with one of the eleven sperm banks approved by the Ministry of Health [13]; after they have chosen the desired donor out of a catalogue, the Israeli clinic orders his semen. Since each patient has to receive personal approval and chooses her desired donor, it can be regarded as 'private import', though mediated by the clinic. There are no unregulated or informal sperm donation services; however, there are three websites for finding a partner for having a joint baby under a legal contract.

\section{Estimating the Number of Sperm Donors in Israel}

The regulation of sperm banks in Israel is minimal, and there are two documents on the subject posted on the Ministry of Health websites; these documents appear in the reference list. One deals with the conditions for approving men as sperm donors and who is entitled to receive sperm donations [14], and the other includes clause 33 , which relates to disinfection and sterilization of medical instruments as well as to procedures for hospitalization and discharge/release of patients [15]; these procedures were written in 1940, long before sperm banks began to operate, 8 years before the establishment of the state of Israel, and there is no reference to fertility issues. Minimal amendments were undertaken following the recognition of the threat of HIV and these appear in a third document [16]. A fourth document includes recommendations of the Public Committee for the Constitutional Regulation of Fertility and Procreation in Israel submitted to parliament [17].

In 2014 there were sixteen sperm banks operating in Israel; thirteen of these are public banks in public hospitals and three are private clinics that are connected to other banks worldwide. The private sperm banks offer both Israeli and non-Israeli sperm donors; the latter are presented via a link to the website of an international sperm bank with which the sperm bank is connected. The relevant data of the number of sperm donors is kept confidential by each sperm bank, and no data sharing exists among the banks or between each bank and the Ministry of Health. Not only are official records of DI treatments conducted annually not methodically kept, but this is also deliberate on the part of the doctors who wish to avoid provoking criticism by rabbinical authorities of offering DI to unmarried women [18]. 
Table 1. Estimated number of sperm donors in each sperm bank

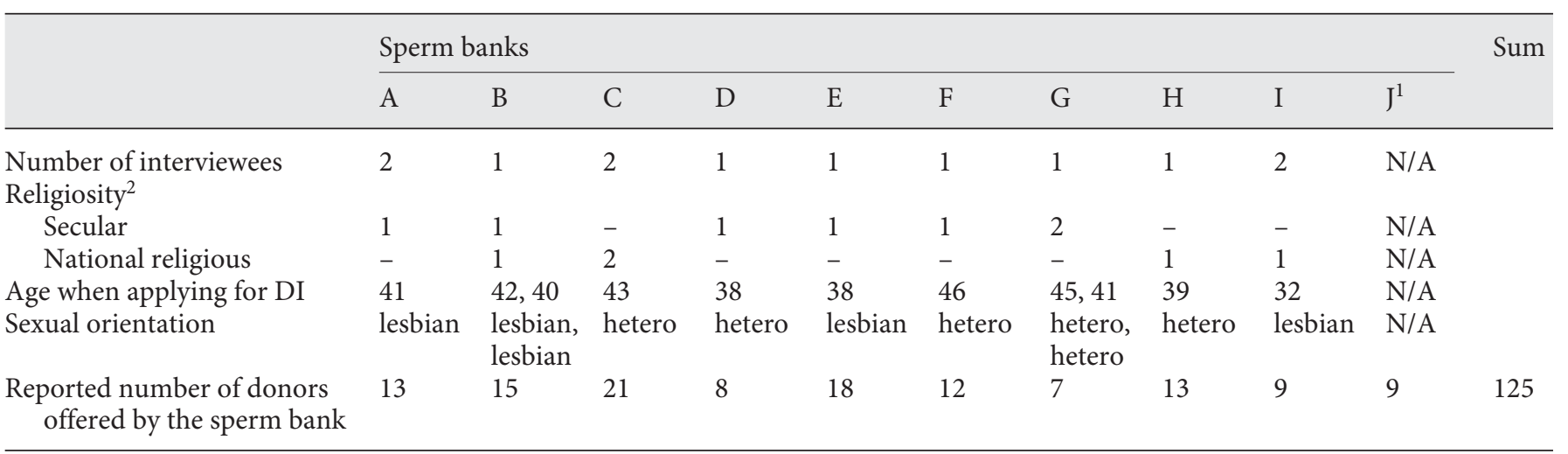

$\mathrm{N} / \mathrm{A}=$ Not available.

${ }^{1}$ The estimate in this bank is based on the manager's answer to a journalist interview, where he said they have a one-digit number of donors. Here the maximal one-digit number was considered, however the exact number may be lower.

${ }^{2}$ No ultra-Orthodox interviewees were identified. There are numerous restrictions to internet use and most young men and women are married off by their family usually at the ages of 18-21. Bringing a child out of wedlock would lead to severe negative sanctions by community and close family.

Table 1 presents the number of available sperm donors reported by the interviewees. Since data were elicited only for nine banks, the number of donors in a tenth bank was estimated as nine, the maximal number that can be estimated after its director told a journalist in an interview that they have a 'one-digit number of donors'. The three remaining banks are located in the periphery of the country, and therefore it is likely that they, too, have a onedigit number of donors.

It is estimated that all thirteen public sperm banks operating in Israel together have about 140 donors; this number is relatively constant since there are only few new donors joining the pool yearly, as would be the optimal case. Since it is likely, as one of the senior fertility experts commented, that an unknown number of donors donate at more than one bank, in spite of the commitment they are asked to sign to refrain from doing so [6], the number may drop to 50, as this expert estimated. Indeed, one of the two interviewed donors admitted he has been donating to two banks concurrently. According to the report submitted to the Israeli parliament, $42 \%$ of the donors are students, $37 \%$ are soldiers doing their compulsory military service, and the remaining $20 \%$ are older men who have finished their occupational training or studies. Although the Ministry of Health recommends limiting the number of pregnancies assisted by one donor, there is no specific limit; furthermore, it is difficult and even impossible to enforce the limit. Hence, the director of each sperm bank has the final decision regarding this dilemma, with most of them stating that they aim for a maximum number of ten children per donor [6].

According to the estimates of the Israeli Ministry of Health, more than 1,200 children are born with the aid of DI each year. Since the overall delivery rate from DI is $14 \%$ per cycle [19], it is estimated that 8,570 DI treatment cycles are conducted yearly. This number is very high relative to other countries: in the UK 4,452 DI treatment cycles were conducted in 2012 [20] and in Canada more than 5,500 DIs are conducted yearly [21]. The large number of DIs per capita is attributed to the pronatalist ideology: the fertility rate is 3 , almost double the rate (1.74) in OECD countries. The family and childbearing are of supreme significance for Jewish Israelis, and hence the national health insurance fully subsidizes fertility treatments for the first and second child for all Israeli women. Religious Jews wish to observe the imperative to increase and multiply', and it is not uncommon for ultra-Orthodox families to have 12-14 children and for modern Orthodox families to have 5-6. Moreover, the more children, the greater the prestige and honor for the parents.

The Jewish population in Israel in 2014 was 6.2 million people [22]. According to the British Fertility Society (BFS), a minimum of 500 sperm donors is necessary in order to have 4,000 treatment cycles each year, and a single donor should not donate to more than ten families [23]. However, according to Human Fertilisation \& Embryology Authority figures, the new donors who register yearly with the Authority make up only about half of this 
minimal number $[20,23]$. The American Society for Reproductive Medicine (ASRM) recommends that in a population of 800,000 , limiting a single donor to no more than 25 births would avoid any significant increased risk of inadvertent consanguineous conception [24]. Dividing 6.2 million Jewish citizens by the recommended 800,000 gives 7.75 - if we multiply this ratio by 25 births as recommended by the ASRM, the result is 194 births; this is one sixth of the estimated number of donor-conceived births, 1,200 yearly. Another way to evaluate the 'donor squeeze' can be calculated by dividing 800,000 by 25 births which results in 32,000, whereas dividing 6,200,000 Jews living in Israel in 2014 by 1,200 donor-conceived children yields 5,166 ; dividing 32,000 by 5,166 also gives 6.2 , this means that the 'load' on each donor is considerably much larger than that recommended by the ASRM. The extant donor pool would be sufficient if there were only 194 children born with the aid of DI. If BFS recommendations are implemented properly, dividing 8,570 yearly DI treatment cycles by 140 donors gives 61 , which is six times larger than the maximum 10. Calculations made by both the ASRM and the BFS lead to a similar conclusion: the minimum number of Israeli donors must be at least six times greater than it is. The optimal number should be even larger owing to Israel's high population density. Any calculation of the maximal number of families that can be created by one donor should take into consideration the population size and also its geographical dispersal [12, 23]. It was also proposed that the donors, the recipients and the public should be involved in determining this number as well [23]. The Netherlands have been used as an example of a country where one donor donates up to 25 families, and note that because of the larger population in the UK as well as its wider geographical dispersal, the UK can judiciously consider increasing the number to 15-20 families per donor [23]. In contrast to the British population, the Israeli population is small, its population density is very high (359 people $/ \mathrm{km}^{2}$ as compared to 32 in the US or 261 in the UK). There are also strong assortative mating patterns, hence the recommended number of families per donor should be much lower in Israel in order to minimize unwitting incestuous relationships.

\section{The Banks' Disrespectful Treatment of Their \\ Prospective and Actual Donors}

As to the lived experience of being a donor, two interviews are unquestionably not representative and insufficient to draw any reasoned conclusions. However, some of the donors' thoughts and experiences are presented here for the purpose of triggering introspective investiga-

Jewish Law and Private Import of Sperm of Non-Jews by Israeli Women tion of management practices by banks. Both donors reported during the interview that after the first screening on the phone, they were invited to a personal interview and were told to bring their military documents as well. Regarding the first selection phase, one of the donors said he was somewhat surprised that the secretary who spoke to him in a previous telephone conversation did not keep his name and contact details and did not send him the application form although she had asked him for his e-mail address. After the genetic testing, each donor was asked to return and to fill in a questionnaire; no interview was conducted with a mental health specialist, presumably because the banks assume that the military service record filters out men with mental disorders. What was similar between the two narratives is that both donors felt uncomfortable talking to the female secretary, not because of her gender but rather because, as they put it, 'I felt like I was being interrogated by a policeman', 'I felt like I had done something wrong. They were also embarrassed when they were asked to provide samples while placed in a booth with thin plasterboard walls situated in the center of the laboratory near all the female lab technicians, rather than in a remotely situated back room.

\section{Discussion}

Over the past years various cases have been documented where religious or cultural practices impeded women's health or dignity, e.g. vaginal douching among Muslim women for the sake of ghusl [25], using misoprostol as an abortifacient by Saudi Arab women [26] or genital mutilation among African communities [27]. The present article supplements this literature and exposes the difficulties of Jewish Israeli women in obtaining adequate DI treatments owing to fundamental religious prohibitions. Specifically, the present article addresses the question of why many Israeli Jewish women, both married and nonmarried, secular as well as religious, choose to privately import non-Jewish sperm. This preference is based on two main rationales: for the religious women the rabbinical prohibition against 'spilling out of sperm', and for all Israeli DI patients the fear of an incestuous relationship between future donor offspring. The prohibition on sperm expulsion results in a severe scarcity of Israeli donors, and the estimated number of available sperm donors in Israel is 50 as the lowest estimate and 140 as the best.

According to one of the previous reports of the State Comptroller, it is not uncommon in Israeli sperm banks 
that semen of a single donor produces 18-25 births; the sperm banks also violate the Health Ministry's prohibition against receiving donations from married men [28]. Owing to the lack of Health Ministry public records regarding these sensitive issues, the data collection included a literature review of the scant extant literature combined with information elicited from DI patients and sperm donors. Rabbinical instructions as presented in scientific articles have not paid adequate scholarly attention to DI practices for non-married women. On the micro-level of the specific articles reviewed above, a major reason may be that the writers and researchers are religiously observant themselves, hence it is reasonable to assume a potential inner conflict between their personal religious-cultural attitudes and their professional practice as well as the content of their academic publications. However, on the macro-level, for Jewish Israeli society, non-married women are stigmatized as deviant and inferior. As in Belgium and several other countries [29], there is no professional association for infertility counsellors in Israel, and hence there are no specific guidelines for infertility counseling. Jewish non-married women who wish to have a child who is legitimate according to Halakha, facing a void in rabbinical guidance and hence an anomie, tend to follow instructions that were originally formulated for married women.

When applying for DI service in Israel, there is a considerable and solid basis for the incest concern, however there is no national center that gathers information about the donors and the donor-conceived children. Each sperm bank manages its own lists, and these internal records are not shared with other banks or with the Ministry of Health. The estimated number of 50 Israeli sperm donors as in the worst scenario, or the 140 as in the relatively best scenario, calls for reconsidering the current public presentation of the subject as well as the insensitive attitude toward the donors. Although it is recommended that the maximal number of children conceived by the same donor should not exceed ten [23], in Israel there is a concern that the number of offspring for each donor may be 10 times larger. Rabbi Dr. Halperin, who was in charge of Ethics at the Israeli Health Ministry until the end of 2014, evaluated the chances of a young person meeting his/her half-sibling of the opposite sex as almost certain [17]. Referring to the lack of state control of sperm donations, he stressed that it is not impossible for a donor to have 100 offspring. Rabbi Dr. Halperin continued his evaluation: assuming there are 500,000 Jewish citizens in the age range of 16-26 and 100 of them may be the offspring of a specific donor, each donor-conceived child may meet his/her half-sibling during random acquaintances with 5,000 people of this age range. Continuing this trend, one could infer that if one-third to one-half of them is of the opposite sex, the chances for a romantic relationship with a half-sister or half-brother are very high. Therefore, the Israeli Ministry of Health is strongly advised to establish an appropriate data collection authority so that records of donor offspring would become available in the utmost confidentiality.

\section{Conclusions}

In light of the multiplicity of patients of diverse ethnic and religious origins in the US and Europe, fertility experts are doing their best to be attentive to their unique cultural beliefs and practices. The present article contributes to the exploration of the religious and cultural context of the motives behind the reproductive consumerism of Israeli DI patients, which fuels the private import of sperm donations. It is proposed that due to the severe scarcity of donors in Israel, a reconsideration of the extant prohibitions should be made; rabbinical laws should be adjusted to contemporary ART and view sperm donations as contributing to the ability of Jews to 'increase and multiply' rather than as a sinful deed. The finding regarding the severe shortfall of donors highlights the need to implement the recommendations for increasing the number of donors: those aimed at increasing the pool (improved advertising, public awareness, etc.) and those aimed at decreasing attrition rates (improved efficiency of first response to enquiries, adjusting lab availability times to potential donors' convenience, etc.) [23]. Alongside the insights gained by the Israeli case, the article also raises the importance of conducting appropriate donor recruitment and maintenance strategies as well as respectful interpersonal interactions with the donors and of affording them greater privacy and confidentiality during sample collection. Improving donor recruitment and maintenance practices is expected to address the problem of donor shortfall in Israel as well as in many other clinics in the US and Europe.

\section{Disclosure Statement}

The author declares no conflict of interests of any kind. 


\section{References}

$>1$ Landau R, Weissenberg R, Madgar I: Older single mothers assisted by sperm donation and their children. Hum Reprod 2007;22: 2784-2791.

-2 Mor-Yosef S, Schenker JG: Sperm donation in Israel. Hum Reprod 1995;10:965-967.

$\checkmark 3$ Carmeli YS, Birenbaum-Carmeli D: Ritualizing the 'natural family': secrecy in Israeli donor insemination. Sci Cult (Lond) 2000;9: 301-324.

-4 Ivry T: Halachic infertility: rabbis, doctors, and the struggle over professional boundaries. Med Anthropol 2013;32:208-226.

$\checkmark 5$ Landau R: Religiosity, nationalism and human reproduction: the case of Israel. Int J Sociol Soc Policy 2003;23:64-80.

6 Mey-Ami N: A committee report to the Knesset. Sperm donation in Israel (in Hebrew). 2005. Retrieved December 20, 2014 from http://www.knesset.gov.il/mmm/data/pdf/ m01527.pdf.

7 Jakobovits Y: Assisted reproduction through the prism of Jewish law. Retrieved December 21, 2014 from http://ou.org.s3.amazonaws. com/publications/ja/5765/5765spring/ Prism.pdf.

8 Pinto-Correia C: The Ovary of Eve: Egg and Sperm and Preformation. Chicago, University of Chicago Press, 1997.

$>9$ Moore LJ: Extracting men from semen: masculinity in scientific representations of sperm. Soc Text 2002;20:91-119.

$>10$ Schenker JG: Human reproduction: Jewish perspectives. Gynecol Endocrinol 2013;29: 945-948.

11 Grazi RV, Wolowelsky JB: The use of cryopreserved sperm and pre-embryos in contemporary Jewish law and ethics. Jewish Law. Retrieved December 18, 2014 from http://www. jlaw.com/Articles/semen.html.

12 Hamilton M: Sperm donation in the United Kingdom in 2010. Hum Fertil (Camb) 2010; 13:257-262.
13 State of Israel Ministry of Health: A list of sperm banks approved by the Ministry of Health (in Hebrew). Retrieved February 14, 2015 from http://www.health.gov.il/subjects/ med_inst/sperm_bank/documents/sperm banks_abroad.pdf.

14 State of Israel Ministry of Health: Sperm donation - sperm bank. Retrieved February 14, 2015 from http://www.health.gov.il/English/ topics/fertility/pages/sperm-bank.aspx.

15 State of Israel Ministry of Health: Public health ordinance, 1940 (in Hebrew). Retrieved February 14, 2015 from http://www. health.gov.il/LegislationLibrary/sherutei03. pdf.

16 State of Israel Ministry of Health: Sperm bank regulations, 1992 (in Hebrew). Retrieved August 9, 2015 from http://www.health.gov.il/ hozer/mk34_1992.pdf.

17 Public Committee for the Constitutional Regulation of Fertility and Procreation in Israel: A committee report to the Knesset: Recommendations of the Public Committee for the Constitutional Regulation of Fertility and Procreation in Israel (in Hebrew). Retrieved January 3, 2015 from http://www.health.gov. il/PublicationsFiles/BAP2012.pdf.

18 Kahn SM: Reproducing Jews. Durham, Duke University Press, 2000.

19 Cohlen B, Ombelet W: Intra-Uterine Insemination: Evidence-Based Guidelines for Daily Practice. Boca Raton, CRC Press, 2013.

20 Human Fertilisation \& Embryology Authority: Fertility treatment in 2012: trends and figures. Retrieved February 13, 2015 from http:// www.hfea.gov.uk/docs/FertilityTreatment2012TrendsFigures.PDF.

21 Stechyson N: Part 3: Few Canadian sperm donors force couples to head south. Retrieved February 13, 2015 from http://www.calgaryherald.com/health/Part+Canadian + sperm + d onors+force+couples+head+south/8947753/ story.html.
22 Central Bureau of Statistics, Israel: Population, by population group (in Hebrew). Retrieved December 18, 2014 from http://www. cbs.gov.il/publications15/yarhon1214/pdf/ b1.pdf.

23 Hamilton M, Pacey A, Tomlinson M, Brison D, Shaw L, Turner C, Witjens L, Morris P, Brown C, Montuschi O, Adams J, Lieberman B, Speirs J: Working Party on Sperm Donation Services in the UK: report and recommendations. Hum Fertil (Camb) 2008;11: 147-158.

24 Practice Committee of American Society for Reproductive Medicine; Practice Committee of Society for Assisted Reproductive Technology: Recommendations for gamete and embryo donation: a committee opinion. Fertil Steril 2013;99:47-62.

25 Erbil N, Alışarlı A, Terzi HC, Özdemir K, Kuş Y: Vaginal douching practices among Turkish married women. Gynecol Obstet Invest 2012; 73:152-157.

26 Alsibiani SA: Use of misoprostol for self-induced medical abortions among Saudi women: a call for attention. Gynecol Obstet Invest 2014;78:88-93.

27 Puppo V: Can Female genital cosmetic surgery be considered or classified as female genital mutilation type IV?. Reply to: A. Ostrzenski: Vaginal rugation rejuvenation (restoration): a new surgical technique for an acquired sensation of wide/smooth vagina. Gynecol Obstet Invest 2012;73:48-52. A rebuttal. Gynecol Obstet Invest 2013;75:215-216.

28 State Comptroller Report: Violation of rules and a lack of control over sperm banks (in Hebrew). Retrieved December 15, 2014 from h t t p: / / w w w.ynet.co.il/articles / 0,7340,L-3397738,00.html.

29 Indekeu A, Rober P, Schotsmans P, Daniels KR, Dierickx K, D'Hooghe T: How couples' experiences prior to the start of infertility treatment with donor gametes influence the disclosure decision. Gynecol Obstet Invest 2013;76:125-132. 